\title{
Miliaire tuberculeuse
}

\section{Miliary tuberculosis}

\section{Mzabi · B. Margo $\cdot$ P. Ray}

Reçu le 13 janvier 2012 ; accepté le 20 janvier 2012

(C) SFMU et Springer-Verlag France 2012
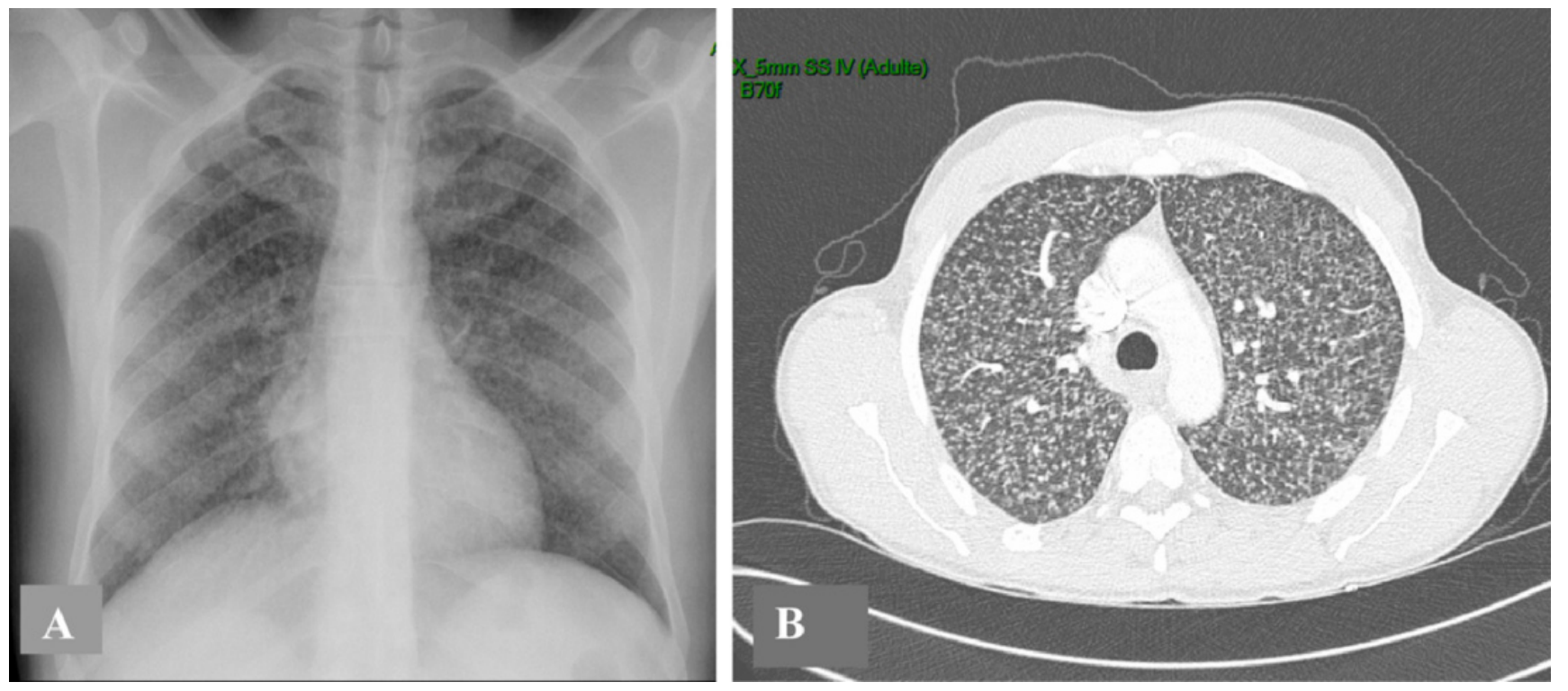

Fig. 1 A : radiographie thoracique de face ; B : scanner en coupes parenchymateuses

Un patient d'origine malienne de 41 ans est admis aux urgences pour une toux fébrile depuis trois semaines associée à une perte de poids. La radiographie (Fig. 1A) retrouve un aspect typique de miliaire avec des micronodules dissé- minés, qui dans le contexte est fortement évocatrice de tuberculose (même si le patient n'était pas bacillifère). Le scanner (non utile en urgence) confirme ces micronodules (Fig. 1B) et ne met pas en évidence d'autres anomalies sémiologiques.

L. Mzabi $\cdot$ B. Margo $\cdot$ P. Ray $(\bowtie)$

Service d'Accueil des urgences,

Groupe hospitalier Tenon-Saint-Antoine,

4, rue de la Chine, F-75020 Paris, France

e-mail : patrick.ray@psl.aphp.fr

Université Pierre-et-Marie-Curie-Paris VI, 4, place Jussieu,

F-75005 Paris, France 